\title{
Comparing the Support-Efficacy Model among Centenarians Living in Private Homes, Assisted Living Facilities, and Nursing Homes
}

\author{
G. Kevin Randall, ${ }^{1}$ Peter Martin, ${ }^{2}$ Maurice MacDonald, ${ }^{3}$ Jennifer Margrett, ${ }^{2}$ \\ Alex J. Bishop, ${ }^{4}$ and Leonard W. Poon ${ }^{5}$ \\ ${ }^{1}$ Department of Family and Consumer Sciences, Bradley University, Peoria, IL 61625, USA \\ ${ }^{2}$ Department of Human Development and Family Studies, Iowa State University, Ames, IA 50011, USA \\ ${ }^{3}$ School of Family Studies and Human Services, Kansas State University, Manhattan, KS 66506, USA \\ ${ }^{4}$ Human Development and Family Science Department, Oklahoma State University, Stillwater, OK 74078, USA \\ ${ }^{5}$ Institute of Gerontology, The University of Georgia, Athens, GA 30602, USA \\ Correspondence should be addressed to G. Kevin Randall, krandall@bradley.edu
}

Received 10 February 2011; Accepted 26 April 2011

Academic Editor: Bo A. Hagberg

Copyright (C) 2011 G. Kevin Randall et al. This is an open access article distributed under the Creative Commons Attribution License, which permits unrestricted use, distribution, and reproduction in any medium, provided the original work is properly cited.

\begin{abstract}
We investigated the influence of social relations on health outcomes in very late life by examining the support-efficacy convoy model among older adults who resided in three different residential environments (centenarians in private homes, $n=126$; centenarians in assisted living facilities, $n=55$; centenarians in nursing homes, $n=105$ ). For each group, path analytic models were employed to test our hypotheses; analyses controlled for sex, mental status, education, perceived economic sufficiency, and activities of daily living. The hypothesized relationships among the models' variables were unique to each of the three groups; three different models fit the data depending upon residential environment. The direct and indirect effects of social relations assessments were positive for the mental and physical health of very old adults, suggesting that participants welcomed the support. However, residential status moderated the associations between the assessments of social relations, self-efficacy, and both outcomes, physical and mental health.
\end{abstract}

\section{Introduction}

For older adults, the important relationship between social resources and physical and mental health outcomes is well established [1-5]. However, as the proportion of oldestold adults in the USA increases, particularly centenarians, and more research attention is given to their study $[6,7]$, theoretically driven investigations of resources necessary for adaptation to changes associated with advanced age are required $[8,9]$. Levitt $[10]$ reviewed work focusing on social development across the life span and recommended the social convoy model as a general or unifying model. In addition, Seeman and Crimmins [11] conducted a review focusing on the effects of the social environment on health and aging from the perspective of both epidemiology and demography. Based on their extensive literature review, including the early work of Antonucci and Jackson [12], they posited a biopsychosocial model of health and aging that included the influence of structural and functional assessments of social relationships on physical and mental health outcomes through psychological characteristics such as self-efficacy.

Recently, Antonucci et al. outlined suggested modifications of the original convoy model of social support based on two decades of empirical and theoretical studies (see Figure $1 ;[13]$ ). Their social support-efficacy model posits a specific mediator, self-efficacy, through which social relations influence health outcomes. In addition, Antonucci et al., as well as Seeman and Crimmins [11], emphasized that situational or contextual experiences are considered important influences on the association among social relations, selfefficacy, and health outcomes for older adults [13]. 


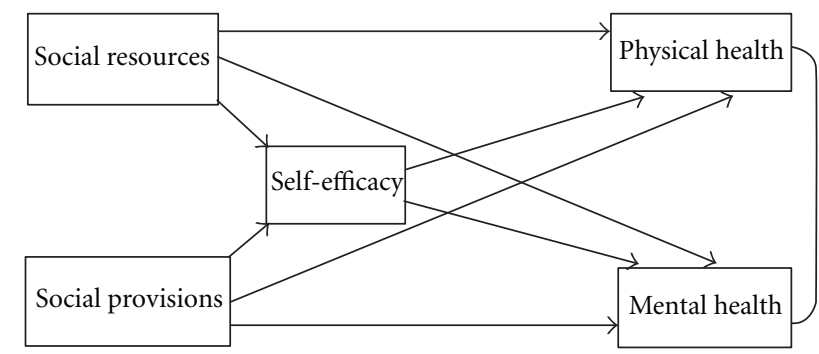

Figure 1: The study's conceptual model was based on the theoretical work of Antonucci et al. [13].

For very old adults, residential setting (e.g., private home, assisted living facility, or nursing home), one assessment of contextual experience, is very salient to the constructs of the support-efficacy model [14-16]. Long-term care is often needed by older adults. It is estimated that by 2050, the total number of individuals subscribing to paid long-term care, whether at home or in some type of residential care, will likely double from 13 million in the year 2000 to 27 million [17]. According to a 2009 report by The National Center for Assisted Living, more than 900,000 adults, whose average age was 86.9 years, resided in assisted living facilities [18]. Regarding nursing home care, researchers found that the number of individuals receiving such care, on any given day, rose from 1.28 million in 1977 to 1.63 million by 1999, a 27\% increase [19]. Bowling and Grundy reviewed literature focused on the association between older adults' social resources and mortality in population-based longitudinal studies [20]. They found substantial evidence for the relationship between social support, social network structure, health status, mortality, and likelihood of entry into institutional care.

Regarding the moderating role of residential status, empirical research has demonstrated that measures of social relations, including structural (i.e., social networks) and functional (i.e., social provisions) assessments, differ across residence status $[16,20]$. Thus, the current study's purpose was to specify and test a version of Antonucci and colleagues' [13] mediating model (see Figure 1) using cross-sectional data from participants in the Georgia Centenarian Study [21] who resided in three distinct living environments: private homes, assisted living facilities, and nursing homes.

Close social relationships received much attention in the literature over the past decades both from a theoretical $[13,22,23]$ and empirical $[3,24-26]$ perspective resulting in strong evidence that older adults with high levels of social resources enjoy better health (physical and mental) than those lacking in close relationships. Convoy, according to Antonucci et al., depicts the close relationships that surround an individual and promote positive development [13]. Social relations, a term often used to define and identify convoy relationships [24], may be operationalized to encompass social networks (a structural assessment) and social support (a functional assessment) [27]. Structural assessments of convoy members include measures of network size, member type (e.g., friend or family member), network members' geographical propinquity, and frequency and type of contact with network members. Functional assessments address the question of what type of support network members provide [28], such as instrumental or emotional support. Krause [29] reviewed over a dozen different types of support from the literature. The current study included both structural and functional assessments of social relations in the tested model.

The literature calls for investigations of mediating mechanisms through which social relationships influence health outcomes, in particular assessments of self-efficacy, human agency, mastery, competence, and control $[13,30]$. Conceptually, perceived control over one's life events and conditions is closely related to various measures of competence such as internal locus of control, mastery, and selfefficacy [2, 24, 31]. According to Ross and Sastry [32], perceived control may tap the same underlying construct as self-efficacy. Over time, contact with significant members of one's social network and the different types of support provided may increase an individual's sense of worth and ability to influence the situational environment. This study featured a measure of self-efficacy, competence as measured by the NEO PI-R $[33,34]$, as the mediating mechanism through which social relations influenced health outcomes. The competence facet, from conscientiousness, addresses how capable or effective an individual feels.

The current study extended the literature by investigating the support-efficacy model with very old adults (i.e., centenarians) and by examining the moderating influence of living environment (e.g., centenarians in private homes, in assisted living facilities, and in nursing homes). Bowling and Grundy challenged researchers to consider influential variables that need to be controlled and intervening variables that might explain such associations [20]. Our analyses controlled for sex, education, perceived economic sufficiency, and instrumental activities of daily living in our analyses [35, 36]. Based on the literature describing the various reasons for residing in a private home, an assisted living facility, and a nursing home (e.g., loss of spouse; decrease in functional, physical, or mental capacity), we hypothesized that the model would fit the data uniquely for each subsample because the living environments and the contextual situations of the participants influence their physical and mental health differentially [37-40]. How the relationships between the models' variables differ by residence status was a research question we investigated.

\section{Method}

2.1. Participants and Procedures. Data for this study came from a Georgia population-based sample of centenarians and octogenarians collected between 2002 and 2005. The sample, comprised of adults aged 98 years and older, was based on a census from a 44-county northern Georgia region including all skilled nursing and personal care facilities. In addition, registered voter lists and corroborating birth date information was also used to identify participants in that region. A refusal to participate rate was not possible to estimate due to the complexities of the sampling strategy. Of the estimated 1244 eligible centenarians in the population, $19.2 \%$ participated, whereas 135 who declined to participate 
were found to be age eligible. Thus, an effective response rate has been estimated at $63.9 \%$ and nonresponders were very similar in terms of certain demographics (age, gender, and race) to final participants. Also, no substantial differences in cognitive status were expected as the sampling strategy included sufficient participants from institutional settings. The Georgia Centenarian Study, Phase 3 investigated factors related to survival and functioning of centenarians. Further details on the study's sampling, data collection, and design are provided by Poon and colleagues [21].

Thus, 158 cognitively intact, community-dwelling, or institutionalized near-centenarians and centenarians (98 years and older; average age was 99.82 years; range was from 98 to 109) were included in this study. Of the participants, $78.5 \%$ were female, $85 \%$ were White and $15 \%$ Black, and $85 \%$ were widowed, whereas only $6 \%$ were married.

\subsection{Measures}

2.2.1. Control Variables. Analyses controlled for participants' sex, mental status, activities of daily living, education, and perceived economic status. For sex, males were coded " 0 " and females "1." The Mini-Mental Status Examination (MMSE, [41]) was used to control for cognitive ability (mental status); higher scores indicated greater ability. Two commonly used subscales, instrumental activities of daily living (seven items), and physical activities of daily living (six items) were combined to create the self-care capacity assessment, activities of daily living (ADLs, [42]). An example of a question asked included "Can you do your housework?" and was scaled so that 2 = without help (can clean floors, etc.), 1 = with some help (can prepare some things but unable to cook full meals yourself), or $0=$ are you completely unable to prepare any meals? Cronbach's alpha for this measure was .88 , and it was scaled so that higher scores indicated higher levels of self-care capacity. A single question from the OARS [42] "How well does the amount of money you have take care of your needs?" was used to assess the participant's financial situation (economic sufficiency). This was scaled from 1 (poorly) to 3 (very well).

2.2.2. Dependent Variables. Research has validated a singleitem measure of self-rated physical health as a summary assessment of overall health status, predictive of outcomes such as mortality, BMI, physical activity, and hospitalization among others [43-45]. DeSalvo and colleagues [46] compared the predictive accuracy of a single-item measure of general health with multi-item scales (e.g., mental component summary and physical component summary). They found the single item performed as well as the multi-item measures regarding validity and reliability, in addition to saving time and money over the use of longer instruments. We used an item from the OARS [42] physical health section asking "How would you rate your overall health at the present time?" Responses ranged from 0 (poor) to 3 (excellent). Similar to physical health, numerous studies have employed a global self-rating of mental health $[47,48]$. We assessed self-reported mental health with an item from the OARS [42] asking "How would you rate your mental or emotional health at the present time?" Responses ranged from 0 (poor) to 3 (excellent).

2.2.3. Predictor Variables. Two commonly used measures for assessing social relations among older adults were included in this study: The Social Provisions Scale (SPS, [49]) and social resources [42]. We employed a 12-item short form of the SPS, a functional assessment that asked questions such as "I have close relationships that provide me with a sense of emotional security and well-being" and "There is no one I can turn to for guidance." Items were scaled from 1 (strongly disagree) to 4 (strongly agree); Cronbach's alpha for the scale was .75. Higher scores reflected higher levels of social provisions. Social resources, a structural assessment of social relationships, was measured using one question from the OARS [42]. In particular, this question asked "How many times during the past week did you spend some time with someone who does not live with you; that is you went to see them or they came to visit you, or you went out to do things together?" Responses were coded $0=$ not at all $1=$ once $2=2-6$ times and $3=$ once a day or more. Based upon work previously conducted [16] with this measure and very old adults (i.e., centenarians), we selected a question tapping frequency of network contact because (a) physical limitations (e.g., hearing loss) common with very old adults $[50,51]$ often limit phone or other communication-only contacts and (b) reduction in network size due to mortality-by definition centenarians have outlived peers, spouses, and often children - limits the numbers of individuals in their network. In addition, due to constraints composed by socioemotional selectivity [23], we did not use questions from the social resources section of the OARS asking about the number of phone conversations or number of network members participants knew well enough to visit as very old adults have likely reduced the number of network contacts to the few most salient. Thus, we selected the question above to tap the amount or frequency of contact the participants had with network members in the past week to comprise our structural measure of social relations.

2.2.4. Mediating Variable. The NEO PI-R [34] is a widely used measure that captures participants' impressions of their own personality along the Big Five personality dimensions. Self-efficacy includes an individual's belief in his/her own competence to successfully perform a particular action [31]. In the present study, the competence facet from conscientiousness was used because it taps the degree to which a respondent feels capable and effective. Feeling well prepared to face life and its changes is typical of those who score high on this facet, and the facet is often highly correlated with self-esteem and internal locus of control [34]. Seven items comprised this facet and were scaled from 0 (disagree) to 2 (agree); Cronbach's alpha for this facet was .70.

Descriptive statistics for each of the study's variables, by residential status, and one-way ANOVA's comparing the means across residential status, are provided in Table 1.

2.3. Data Analytic Procedure. Because previous investigations [16] revealed significant differences in social resources 
TABLE 1: Descriptives and ANOVA results for study variables.

\begin{tabular}{lccc}
\hline Variables & Private homes & Assisted living facilities & Nursing homes \\
& $\mathrm{M}(\mathrm{SD})$ & $\mathrm{M}(\mathrm{SD})$ & $101(2.10)$ \\
\hline (1) Age & $99.76(1.71)$ & $100(2.00)$ & $87.6 \%$ female \\
(2) Sex & $76.2 \%$ female & $86 \%$ female & $11.37(8.24)$ \\
(3) Mental status (MMSE) & $20.43(7.09)$ & $19.44(7.87)$ & $11.15(3.59)$ \\
(4) Years of education & $11.65(3.87)$ & $13(3.05)$ & $2.73(.47)$ \\
(5) Economic sufficiency & $2.56(.63)$ & $2.67(.48)$ & $33.98(8.88)$ \\
(6) ADLs & $37.11(7.43)$ & $37.42(7.03)$ & $1.82(.91)$ \\
(7) Physical health & $1.87(.76)$ & $1.85(.62)$ & $1.73(.76)$ \\
(8) Mental heath & $2.02(.62)$ & $5.64(.57)$ & $5.50(1.98)$ \\
(9) Self-efficacy & $5.66(2.09)$ & $1.83(.75)$ & $1.96(.84)$ \\
(10) Social resources & $1.81(.78)$ & $35.24(2.55)$ & $34.39(2.73)$ \\
(11) Social provisions & $35.19(2.15)$ & & $*$ \\
\hline
\end{tabular}

${ }^{*}$ Private homes differed from nursing homes, $P<.05$;

** Private homes and assisted living facilities differed from nursing homes, $P<.05$;

$* * *$ Each was significantly different from the other, $P<.05$.

and social provisions between octogenarians and centenarians living in private homes and among centenarians residing in private homes, assisted living facilities, and nursing homes, we conducted our analyses by subgroup. Based upon Antonucci and colleagues' model [13], we tested a path analytic model for each subgroup. We used path analysis for a number of reasons. First, because of our limited sample size, we employed manifest rather than latent variables to reduce the number of parameters estimated in our models. Second, if necessary, we also wanted to test for model equivalency across our subgroups. Third, our hypotheses called for tests of directionality with self-efficacy as a mediating mechanism. Working with very old adults presents numerous challenges, one of which is locating and assessing participants who often present with numerous hearing, visual, and other medical conditions, in addition to mortality concerns over time [7], resulting in smaller sample sizes. The literature on sample size and covariance structure modeling has addressed the concern of sample size and the number of parameters estimated [52-54]. Jackson concluded that when small sample sizes (he compared sizes of 50,100, 200, 400, and 800) are encountered, assessments of model fit such as chi-square goodness-of-fit and RMSEA, for example, are most sensitive to misspecification and therefore, recommended. In addition, Herzog and Boomsma conducted a Monte Carlo study demonstrating that Swaincorrected estimators were robust to small sample sizes and recommended their use for small sample size research [52]. We used their syntax for use with $\mathrm{R}$ software for each of our final models presented in the Section 3 below, and no differences in fit were found between what we reported and the Swain-corrected estimations. Thus, a path model allowed us to examine model fit, model equivalency between groups, and indirect effects through the mediating mechanism of self-efficacy.

The literature on multiple-sample testing in structural equation modeling argues for establishing a baseline or bestfitting model for each sample first [55]. Kline extends the point and argues that unless an unconstrained model fits well across samples, it makes little sense to test additional constraints [56, page 295]. We first specified and tested the hypothesized support-efficacy model, determining the best model fit for each subgroup (a series of nested model tests examining change in chi-square for each nested model). Analyses were conducted with Mplus Version 5.0 [57] using full-information maximum likelihood (FIML) to handle missing data; overall model fit was assessed by employing the Satorra-Bentler chi-square test statistic that is robust to nonnormality of measures, referred to as the MLR $\chi^{2}$ in Mplus. Model evaluation was based on the chi-square goodness of fit test and other fit indices: the comparative fit index-CFI [58], root mean squared error of approximation (RMSEA, [59]), and the standardized root mean squared residual (SRMR). Values close to .95 for CFI, .08 for SRMR, and .06 for RMSEA suggest that good fit between the observed data and the hypothesized model exists [60, 61]. Nested model testing was conducted according to the procedure outlined in Mplus [57]. Control variables included sex, mental status, perceived economic sufficiency, and activities of daily living.

\section{Results}

3.1. Centenarians in Private Homes. A base model with no degrees of freedom (all possible paths were estimated) was tested. The regression of mental health on social resources was not significant, $(\beta=.13 ; P>.05)$, neither was the regression of mental health on self-efficacy $(\beta=.05 ; P>$ $.05)$. These paths were deleted, and the nested model fit the data well: $\operatorname{MLR} \chi^{2}(2, N=126)=2.36, P=.31, \mathrm{CFI}=.99$; RMSEA $=.04 ;$ SRMR $=.02$. In this model, all specified paths were significant (one-tailed tests); however physical health regressed on social provisions $(\beta=.20 ; P>.05)$ was the weakest path. Thus, for the sake of parsimony, we specified a model without this path: MLR $\chi^{2}(3, N=126)=5.14$, $P=.16, \mathrm{CFI}=.97$; RMSEA $=.08$; SRMR $=.03$. We conducted a nested model test according to L. K. Muthén and B. O. 


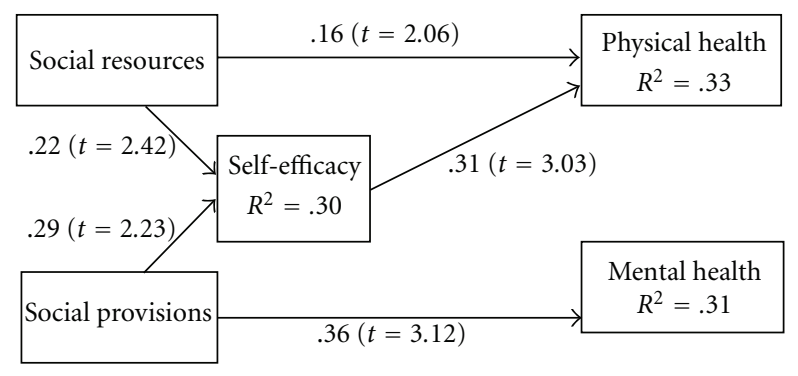

Figure 2: Test results for the support-efficacy model with centenarians residing in private homes; model fit: Satorra-Bentler $\chi^{2}$ $(N=126 ; \mathrm{df}=3)=5.14 ; P=.16$; CFI $=.97$; RMSEA $=.08$; SRMR $=.03$ (using F1ML). Nonsignificant paths deleted; parameter estimates are from the standardized solution. Test of Indirect Effect for Social Resources on Physical Health $(.07 ; t=1.93 ; P=$ .053; two-tailed). Test of Indirect Effect for Social Provisions on Physical Health (.09; $t=1.66 ; P=.097$; two-tailed). Endogenous variables were controlled for sex, mental status, ADLs, education, and economic sufficiency.

Muthén [57]; this model's fit was not significantly different from the model with the path regressing physical health on social provisions: $\Delta \chi^{2}(1 \mathrm{df})=2.50, P=.11$.

The final model (see Figure 2) depicts the most parsimonious, best fitting model to our data following the support-efficacy conceptualization for centenarians residing in private dwellings. Direct effects for social resources on physical health $(\beta=.16 ; P<.05)$ and social provisions on mental health $(\beta=.36 ; P<.05)$ were found in the previous model, whereas in this best-fitting model for centenarians in private homes, no direct effects for social resources on mental health or social provisions on physical health were found. However, consistent with Antonucci and colleagues [13], indirect effects operating through self-efficacy were found both for social resources (.07; $P=.053$; two-tailed test) and social provisions on physical health $(.09 ; P=.097$; twotailed test), whereas no indirect effects were found for either predictor on the outcome mental health.

3.2. Centenarians in Assisted Living Facilities. In the base model, significant predictors of physical health and selfefficacy were found; no predictors were found for mental health. Physical health was predicted by social resources $(\beta=.34 ; P \leq .003)$ and self-efficacy by social provisions $(\beta=.58 ; P \leq .02)$. Based on these results we tested a model deleting the path of social provisions predicting physical health, social resources predicting self-efficacy, and the predictors of mental health except controls. This model fit the data adequately: $\operatorname{MLR} \chi^{2}(5, N=55)=8.93 ; P=.11$; $\mathrm{CFI}=.91$; RMSEA $=.12$; $\mathrm{SRMR}=.06$. However, in addition to the higher value for RMSEA, one of the modification indices looked promising for the regression of mental health on self-efficacy, so we tested a model including this path. This model fit the data well: MLR $\chi 2(4, N=55)=5.29$, $P=.26$, CFI $=.97$; RMSEA $=.08$; SRMR $=.04$. The nested model chi-square test was significant $\left(\Delta \chi^{2}=6.90\right.$, $1 \mathrm{df}, P=.01$ ). We selected the latter model over the former because the Chi-square and the CFI, RMSEA, and SRMR

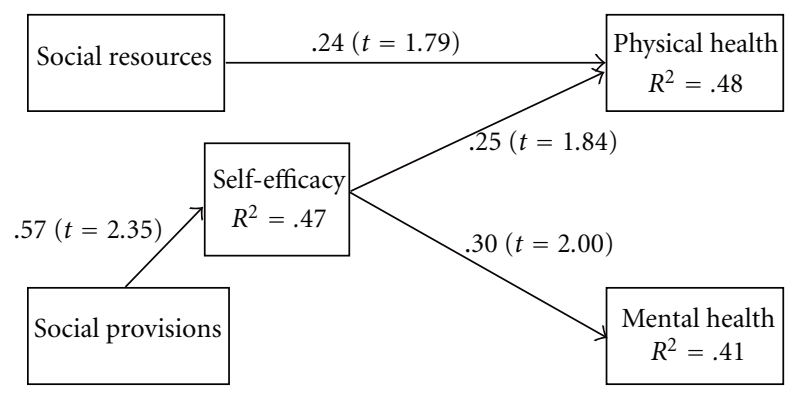

FIGURE 3: Test results for the support-efficacy model with centenarians residing in assisted living facilities; model fit: Satorra-Bentler $\chi^{2}(N=55 ; \mathrm{df}=4)=5.29 ; P=.26$; CFI $=.97$; RMSEA $=$ .08 ; SRMR $=.04$ (using F1ML). Parameter estimates are from the standardized solution; endogenous variables were controlled for sex, mental status, ADLs, education, and economic sufficiency.

indices suggested that it was the better fitting model than the nested model with more degrees of freedom (see Figure 3 ). In addition, we conducted the tests of indirect effects from social provisions to both physical and mental health. The indirect effect on physical health was not significant $(P=$ .18 ), whereas the indirect effect from social provisions on mental health through self-efficacy reached significance for a hypothesized effect ( $P=.05$; one-tailed test).

3.3. Centenarians in Nursing Homes. The base model used in previous analyses could not be tested because the covariance coverage fell below 10 percent (i.e., all variables and pairs of variables have data for at least ten percent of the sample). Inspection of our individual variables led us to delete our measure for economic sufficiency. In addition, when this model was run, difficulties were encountered estimating appropriate standard errors (nonpositive definite matrix) based on the control variable sex. Of the 105 centenarians living in nursing homes, 92 were female and 13 male. Thus, further models for centenarians in nursing homes excluded economic sufficiency and the control variable, sex. No further estimation difficulties were encountered.

In the tested base model, neither exogenous predictor, social resources $(\beta=.20 ; P>.05)$ nor social provisions $(\beta=-.13 ; P>.05)$ significantly predicted self-efficacy. However, both self-efficacy $(\beta=.60 ; P=.01)$ and social provisions $(\beta=-1.09 ; P=.008)$ significantly predicted mental health, whereas only social provisions approached statistical significance predicting physical health $(\beta=.77$; $P=.14)$. Regarding the magnitude of the standardized beta for social provisions, Jöreskog [62] noted that it is possible for a standardized coefficient to be greater than one (e.g., 1.04, 1.40, or 2.08) and that it does not necessarily imply error in the model. However, he did point out that such a finding likely points to multicollinearity in the data. Our measure of ADLs was negatively and highly correlated with social provisions $(r=-.85)$ in this model. Thus, we deleted ADLs from the analysis and found that indeed social provisions significantly predicted physical health $(\beta=.43$; $P=.02$ ), neither measure of social resources predicted self-efficacy, and only self-efficacy predicted mental health 


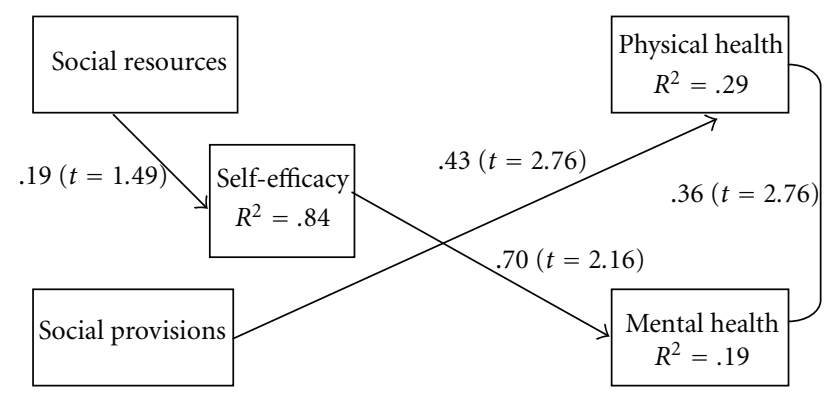

Figure 4: Test results for the support-efficacy model with centenarians residing in nursing homes; model fit: Satorra-Bentler $\chi^{2}$ $(N=105 ; d f=5)=6.33 ; P=.28$; CFI $=.94$; RMSEA $=$ .05 ; SRMR $=.06$ (using FIML). Parameter estimates are from the standardized solution; endogenous variables were controlled for mental status and education.

$(\beta=.70 ; P=.01)$. In this model, $R^{2}$ for physical health was .29; for mental health it was .19, and for self-efficacy it was .84 (see Figure 4). In addition, both mental status and education were significant predictors of self-efficacy. Thus, as a supplemental analysis, we computed a model specifying the indirect effect from these control variables (mental status and education) to mental health through self-efficacy. The standardized indirect effect was $.49(P=.02)$.

\section{Discussion}

This study tested the support-efficacy model [13] for each of three centenarian groups participating in the Georgia Centenarian Study [21]: centenarians residing in private homes, centenarians residing in assisted living facilities, and centenarians residing in nursing homes. A focus of the model is the hypothesized indirect effect of social relations on health outcomes of older adults through the mediating mechanism of self-efficacy. Overall, the study's results supported the hypothesized model. The mediator, self-efficacy, completely mediated the influence of social relationships in two of the three models tested on self-report data from centenarians (i.e., those residing in private homes and assisted living facilities). In particular, how the model worked varied by residential status (i.e., private home, assisted living facility, or nursing home); the relationship among the variables for the best fitting model was different for each residential status.

Three findings, consistent across the three models, merit discussion. First, our results supported the hypothesized positive influence of social relationships on the physical and mental health of centenarians. These findings are consistent with previous research across the life span [20, 63, 64]. However, ambivalent findings about the valence of social support on psychological outcomes have been reported. For example, perceived support is often beneficial whereas actual received support may be detrimental $[65,66]$. We believe our study's positive findings for the influence of social relations on health outcomes for centenarians, regardless of living environment, are best explained by considering the qualitative work of Chen et al. [37]. They developed a grounded theory of elders' decisions to enter assisted living facilities, including the weighing and balancing of gains and losses "to go where the help is" (page 92) - the anticipated outcome of moving. When losses outweighed gains, they went to the help; they moved to a facility. Such a move often includes cognitive, affective, and physical stressors. Often, a move is perceived as loss of independence and is not preferred to the private home, but is preferred relative to entering a nursing home $[38,40,67]$. These decisions and associated stressors also apply when moving from an assisted living facility to a nursing home. We believe that it is possible that centenarians in our study understood the salubrious role social relations provide (whether perceived or received; see [27]) for their independence and ability to live in a private home setting; such support either delays the need to move toward help (maintaining a level of independence for those in private homes) or for those no longer able to remain in a private home, such support could be effective in the transition from private home to assisted living facility. Thus, the direct and indirect effects of social resources (frequency of contact) and social provisions (types of support provided) were positively (i.e., they were welcomed supports) associated with the mental and physical health of our very old participants.

A second finding, for centenarians in private homes and for centenarians in assisted living facilities, consistent with the model and previous research differentiating between the effects of social network and social support variables, is the strong influence of social provisions, compared to the influence of social resources, primarily on outcomes of well being $[36,68]$. Our assessment of social relations tapped the frequency of contact between participants and their network of friends and family, whereas Cutrona and Russell's Social Provisions Scale [49] was designed to assess the type of support provided by others. Because social provisions were self-reported by participants, the measure likely included their perceptions of available support $[69,70]$; it does not necessarily assess support actually provided. We believe that the Social Provisions Scale, with its breadth of functional supports assessed, tapped the appropriate support needed by our participants for the particular stressor experienced, resulting in a strong relationship between the measure and both physical and mental health.

Consistent with the hypothesized model and the literature regarding mediation through self-efficacy, was a third noteworthy finding: the mediating role of self-efficacy between social relations and the health outcomes for centenarians in private homes and assisted living facilities. Intriguingly, for centenarians in assisted living facilities, the influence of social provisions was completely mediated through self-efficacy. The effect on mental health reaches statistical significance for a one-tailed test; the effect on physical health approaches statistical significance for a onetailed test. Cutrona and Russell [49] provided an explanation about the theoretical underpinnings of their Social Provisions Scale that helps explain this finding. Theoretically, both Bandura [31, 71] and Cobb [72, 73] predicted that social support should lead to an individual's self-assessment of confidence or competency. Such assessments of self-efficacy in turn encourage individuals to attempt difficult tasks, work harder, and persist when facing difficult situations. Thus, 
greater levels of self-efficacy could lead to more effective coping and higher levels of physical and mental health. Centenarians in assisted living facilities are surrounded by potential supporters and provisions that are available if needed and called upon [37]. Also, they are not in private homes where they could be isolated or distant from support and they are not in nursing homes where chronic physical and mental health concerns are often experienced. These very old adults, residing in an assisted living facility, may be in the best of situations: they are independent in terms of most if not all activities of daily living and, if needed, social resources in terms of network members' availability and social provisions are close at hand.

Additionally, Holahan et al. [74] proposed and tested a mediation model that posited the indirect effects of social resources on psychological adjustments through personality characteristics such as self-confidence. They found that in situations of high stress the indirect effect model fit the data, whereas in lower stress situations, direct effects were found. It might be that centenarians in our study have been in assisted living facilities for a lengthy period of time and were facing the stressful move to a nursing home. Either explanation of the results fits with the particular effectiveness of the support-efficacy for this group of older adults. In support of this explanation for centenarians in assisted living facilities, the hypothesized mediating model explained the most variance in both outcomes, mental and physical health ( $41 \%$ and $48 \%$, resp.), compared to the models tested for centenarians in other living situations.

Three unique findings of the current study for centenarians in private homes were noted: (a) the influence of social provisions on physical health was completely mediated through self-efficacy, whereas it was not for mental health, (b) the influence of social resources on physical health was partially mediated through self-efficacy, and (c) social resources did not influence mental health directly or indirectly; only social provisions directly influenced mental health. Centenarians in private homes are truly expert survivors [75], and while not necessarily healthy as compared to younger adults, they are likely autonomous individuals [76]. The complete mediation of social support or functional helps through self-efficacy hints to the fact that "learned helplessness" has not become the norm for these individuals. Either they are receiving very appropriate support that does not undermine their self-confidence or they perceive support that exists if they need it. Bandura [31] referred to efficacy expectations or beliefs that one can do or perform particular actions, a belief about personal competence [77]. Once again, the literature addressing why older adults transition to assisted living facilities or nursing homes provided insight into the probable reasons for this mediated path. One factor related to relocation is the need for help with activities of daily living and medication management [78]. Perhaps, for this group of centenarians living in a private home and experiencing higher levels of independence than their peers in assisted living facilities or nursing homes, the frequency of contact with social network members (directly and indirectly influencing physical health) and the particular types of support provided by others' assistance enables them to feel competent or capable of accomplishing the tasks necessary to remain in their residential setting, leading to perceptions of better physical health. In addition, these participants could be healthier than those not residing in private homes. Thus, whatever supportive relationships were in place and active helped the centenarians to maintain a level of physical health concomitant with independent living and associated feelings of self-efficacy. As mentioned above, the work of Holohan et al. [74] demonstrated that indirect effects of social support through personality characteristics such as self-efficacy operated primarily under stressful conditions. It may be that centenarians living in private homes will finish their years in a private setting, at least until near the end of life when their physical health begins to precipitously fail. Perhaps private home dwelling is associated with lower stress levels, thus explaining the direct influence of social provisions on their mental health, and why, regarding their physical health, which is necessary for dwelling in a private home, both direct and indirect influences of social relations were operative. In addition, we believe that this line of thinking may be one explanation for the lack of influence on mental health by self-efficacy either directly or as a mediator; the strong, direct influence of social provisions overrode the influence of the participants' personal perspective of their own mastery. Likely, the stress is low in the presence of such supportive help as centenarians living in private dwellings do so with support from others. When that support is perceived to be available or present, it likely contributes more to their mental health than their own perception of self-efficacy.

For centenarians residing in nursing homes, selfefficacy's lack of association with physical health is a unique finding. Once one resides in a nursing facility, it is likely that a strong sense of self-efficacy is not helpful or advantageous over outcomes where one has minimal influence such as physical health [76]. However, instrumental and received social support are concomitant with nursing home residence and likely explain the direct effect of social provisions on physical health. As mentioned in the results section regarding the supplemental analyses, we did find a strong indirect effect of mental status and education on mental health through self-efficacy. In addition, we mentioned the strong association between social provisions and activities of daily living. Consequently, we deleted activities of daily living from the model because of multicollinearity. These findings agree with a recent meta-analysis of 77 reports based on longitudinal data from community-based samples. It found the strongest predictors of nursing home admission included functional disability, cognitive impairment, and prior nursing home use [14]. At this stage of the life span and in this residential setting, there is likely little centenarians can do regarding their physical health, other than utilizing the direct services of others. However, participants who have higher levels of cognitive ability tend to have higher levels of self-efficacy and in turn higher levels of mental health. This discussion may also provide an explanation regarding the influence of self-efficacy on mental health for centenarians residing in nursing homes. Whereas, for those in private homes, perception of self-efficacy was not found to influence mental health-social provisions tended to directly and 
significantly influence their mental health-for centenarians in nursing homes, perception of self-efficacy mattered. For participants with higher levels of cognitive ability, what they might have control over is how they view their lives or their mental outlook on life $[1,75,76]$.

Our study is not without limitations. First, we examined three distinct groups of centenarians based on residential living status resulting in relatively small sample sizes. Second, our study was cross-sectional in nature; it did not follow very old adults from dwelling in a private home to an assisted living facility, and ultimately to a nursing home, nor was the study able to assess change in the measures over time as proposed by Antonucci et al. [13]. Centenarian studies face difficult design issues because the remaining life expectancy of participants is often less than two years depending upon birth cohort. In addition, we do not know if our participants were in the nursing home for the second or third time with intervals back in private residences or assisted living facilities. Gaugler and colleagues [14] found prior nursing home use to be one of the strongest predictors of nursing home admission. Third, measurement concerns regarding multiple assessments and types of reporting for the constructs studied would reduce possible bias in the results. These limitations provide opportunity for future research to build and expand upon the study and the theoretical model.

The present study added to the existing knowledge base of very old individuals by specifying and testing a version of the support-efficacy model $[11,13]$. In addition, we considered a key situational characteristic of very old individuals near the end of the life span as a moderating influence: residential status (e.g., living in a private home, assisted living facility or a nursing home). The study affirmed the specified relationships between variables of the model; however, specific to this study was the finding that the hypothesized model uniquely fit each group of participants. Future work with very old individuals will be aimed to consider and account for the moderating influence of residence status on the constructs examined: social relations, self-efficacy, and both mental and physical health.

\section{Acknowledgments}

The Georgia Centenarian Study (Leonard W. Poon, PI) is funded by 1P01-AG17553 from the National Institute on Aging, a collaboration among The University of Georgia, Tulane University Health Sciences Center, Boston University, University of Kentucky, Emory University, Duke University, Wayne State University, Iowa State University, Temple University, and University of Michigan. Authors acknowledge the valuable recruitment and data acquisition effort from M. Burgess, K. Grier, E. Jackson, E. McCarthy, K. Shaw, L. Strong and S. Reynolds, data acquisition team manager; S. Anderson, E. Cassidy, M. Janke, and J. Savla, data management; M. Poon for project fiscal management.

\section{References}

[1] D. G. Blazer and C. F. Hybels, "Origins of depression in later life," Psychological Medicine, vol. 35, no. 9, pp. 1241-1252, 2005.
[2] N. Krause, "Social support and feelings of personal control in later life," in Sourcebook of Social Support and Personality, G. R. Pierce, B. Lakey, I. G. Sarason, and B. R. Sarason, Eds., pp. 335-355, Plenum Press, New York, NY, USA, 1997.

[3] J. L. Moren-Cross and N. Lin, "Social networks and health," in Handbook of Aging and the Social Sciences, R. H. Binstock and L. K. George, Eds., pp. 111-128, Academic Press, Burlington, Mass, USA, 6th edition, 2006.

[4] M. Pinquart and S. Sörensen, "Influences of socioeconomic status, social network, and competence on subjective wellbeing in later life: a meta-analysis," Psychology and Aging, vol. 15, no. 2, pp. 187-224, 2000.

[5] M. K. Rohr and F. R. Lang, "Aging well together-a minireview," Gerontology, vol. 55, no. 3, pp. 333-343, 2009.

[6] M. MacDonald, "Social support for centenarians' health, psychological well-being, and longevity," Annual Review of Gerontology and Geriatrics, vol. 27, pp. 107-128, 2007.

[7] L. W. Poon and T. T. Pearls, "The trials and tribulations of studying the oldest old," Annual Review of Gerontology and Geriatrics, vol. 27, pp. 1-10, 2007.

[8] V. L. Bengston, D. Gans, N. M. Putney, and M. Silverstein, "Theories about age and aging," in Handbook of Theories of Aging, V. L. Bengston, D. Gans, N. M. Putney, and M. Silverstein, Eds., pp. 3-24, Springer, New York, NY, USA, 2nd edition, 2009.

[9] V. L. Bengston and K. W. Schaie, Eds., Handbook of Theories of Aging, Springer, New York, NY, USA, 1999.

[10] M. J. Levitt, "Social relations across the life span: in search of unified models," International Journal of Aging and Human Development, vol. 51, no. 1, pp. 71-84, 2000.

[11] T. E. Seeman and E. Crimmins, "Social environment effects on health and aging: integrating epidemiologic and demographic approaches and perspectives," Annals of the New York Academy of Sciences, vol. 954, pp. 88-117, 2001.

[12] T. C. Antonucci and J. S. Jackson, "Social support, interpersonal efficacy, and health: a life course perspective," in Handbook of Clinical Gerontology, L. L. Carstensen and B. A. Edelstein, Eds., pp. 291-211, Pergamom Press, New York, NY, USA, 1987.

[13] T. C. Antonucci, K. S. Birditt, and H. Akiyama, "Convoys of social relations: an interdisciplinary approach," in Handbook of Theories of Aging, V.L. Bengston, D. Gans, N. M. Putney, and M. Silverstein, Eds., pp. 247-260, Springer, New York, NY, USA, 2nd edition, 2009.

[14] J. E. Gaugler, S. Duval, K. A. Anderson, and R. L. Kane, "Predicting nursing home admission in the U.S: a metaanalysis," BMC Geriatrics, vol. 7, article no. 13, 2007.

[15] J. E. Gaugler and R. L. Kane, "Improving practice through research in and about assisted living: implications for a research agenda," The Gerontologist, vol. 47, pp. 83-99, 2007.

[16] G. K. Randall, P. Martin, M. McDonald, and L. W. Poon, "Social resources and longevity: Findings from the Georgia Centenarian Study," Gerontology, vol. 56, no. 1, pp. 106-111, 2010.

[17] Family Caregiver Alliance, 2005, http://www.caregiver.org/caregiver/jsp/content_node.jsp?nodeid=440 .

[18] National Center for Assisted Living, "Resident profile," December 2009, http://www.ahcancal.org/ncal/resources/ Pages/ResidentProfile.aspx .

[19] F. H. Decker, Nursing Homes, 1977-99: What Has Changed, What Has Not? National Center for Health Statistics, Hyattsville, Md, USA, 2005, http://www.cdc.gov/nchs/data/ nnhsd/NursingHomes1977_99.pdf. 
[20] A. Bowling and E. Grundy, "The association between social networks and mortality in later life," Reviews in Clinical Gerontology, vol. 8, no. 4, pp. 353-361, 1998.

[21] L. W. Poon, S. M. Jazwinski, and R. C. Green, "Methodological considerations in studying centenarians: lessons learned from the Georgia Centenarian Studies," Annual Review of Gerontology and Geriatrics, vol. 27, pp. 231-264, 2007.

[22] F. Blanchard-Fields and A. Kalinauskas, "Theoretical perspectives on social context, cognition, and aging," in Handbook of Theories of Aging, V.L. Bengston, D. Gans, N. M. Putney, and M. Silverstein, Eds., pp. 261-276, Springer, New York, NY, USA, 2nd edition, 2009.

[23] L. L. Carstensen, D. M. Isaacowitz, and S. T. Charles, "Taking time seriously: a theory of socioemotional selectivity," American Psychologist, vol. 54, no. 3, pp. 165-181, 1999.

[24] T. C. Antonucci, "Social relations: an examination of social networks, social support, and sense of control," in Handbook of the Psychology of Aging, J. E. Birren and K. W. Schaie, Eds., pp. 427-453, Academic Press, San Diego, Calif, USA, 2001.

[25] L. K. George, "Perceived quality of life," in Handbook of Aging and the Social Sciences, R. H. Binstock and L. K. George, Eds., pp. 320-336, Academic Press, Burlington, Mass, USA, 6th edition, 2006

[26] N. Krause, "Social relationships in late life," in Handbook of Aging and the Social Sciences, R. H. Binstock and L. K. George, Eds., pp. 182-201, Academic Press, Burlington, Mass, USA, 6th edition, 2006.

[27] A. D. Faber and S. Wasserman, "Social support and social networks: synthesis and review," Advances in Medical Sociology, vol. 8, pp. 29-72, 2002.

[28] R. Weiss, "The provisions of social relationships," in Doing Unto Others, Z. Rubin, Ed., pp. 17-26, Prentice Hall, Englewood Cliffs, NJ, USA, 1974.

[29] N. Krause, "Assessing change in social support during late life," Research on Aging, vol. 21, no. 4, pp. 539-569, 1999.

[30] T. L. Bisconti and C. S. Bargeman, "Perceived social control as a mediator of the relationships among social support, psychological well-being, and perceived health," Gerontologist, vol. 39, no. 1, pp. 94-103, 1999.

[31] A. Bandura, "Self-efficacy: toward a unifying theory of behavioral change," Psychological Review, vol. 84, no. 2, pp. 191-215, 1977.

[32] C. E. Ross and J. Sastry, "The sense of personal control: socialstructural causes and emotional consequences," in Handbook of the Sociology of Mental Health, C. S. Aneshensel and J. C. Phelan, Eds., pp. 369-394, Plenum, New York, NY, USA, 1999.

[33] P. T. Costa and R. R. McCrae, Revised NEO Personality Inventory (NEO PI-R) and NEO Five-Factor Inventory (NEO-FFI) Professional Manual, Psychological Assessment Resources, Odessa, Fla, USA, 1992.

[34] R. L. Piedmont, The Revised NEO Personality Inventory: Clinical and Research Applications, Plenum Press, New York, NY, USA, 1998.

[35] T. C. Antonucci, J. E. Lansford, H. Akiyama et al., "Differences between men and women in social relations, resource deficits, and depressive symptomatology during later life in four nations," Journal of Social Issues, vol. 58, no. 4, pp. 767-783, 2002.

[36] T. C. Antonucci, R. Fuhrer, and J. F. Dartigues, "Social relations and depressive symptomatology in a sample of community-dwelling French older adults," Psychology and Aging, vol. 12, no. 1, pp. 189-195, 1997.

[37] S. L. Chen, J. W. Brown, L. C. Mefford et al., "Elders' decisions to enter assisted living facilities: a grounded theory study,"
Journal of Housing for the Elderly, vol. 22, no. 1-2, pp. 86-103, 2008.

[38] E. K. Rossen, “Assessing older persons' readiness to move to independent congregate living," Clinical Nurse Specialist, vol. 21, no. 6, pp. 292-296, 2007.

[39] D. Street, S. Burge, J. Quadagno, and A. Barrett, "The salience of social relationships for resident well-being in assisted living," Journals of Gerontology. Series B, vol. 62, no. 2, pp. S129-S134, 2007.

[40] J. P. Tracy and S. DeYoung, "Moving to an assisted living facility: exploring the transitional experience of elderly individuals," Journal of Gerontological Nursing, vol. 30, no. 10, pp. 26-33, 2004.

[41] M. F. Folstein, S. E. Folstein, and P. R. McHugh, “'Mini mental state'. A practical method for grading the cognitive state of patients for the clinician," Journal of Psychiatric Research, vol. 12, no. 3, pp. 189-198, 1975.

[42] G. G. Fillenbaum, Multidimensional Functional Assessment of Older Adults: The Duke Older Americans Resources and Services Procedures, L. Erlbaum Associates, Hillsdale, NJ, USA, 1988.

[43] K. B. DeSalvo, W. P. Fisher, K. Tran, N. Bloser, W. Merrill, and J. Peabody, "Assessing measurement properties of two singleitem general health measures," Quality of Life Research, vol. 15, no. 2, pp. 191-201, 2006.

[44] M. Jylhä, S. Volpato, and J. M. Guralnik, "Self-rated health showed a graded association with frequently used biomarkers in a large population sample," Journal of Clinical Epidemiology, vol. 59, no. 5, pp. 465-471, 2006.

[45] J. E. Rohrer, D. C. Herman, S. P. Merry, J. M. Naessens, and M. S. Houston, "Validity of overall self-rated health as an outcome measure in small samples: a pilot study involving a case series," Journal of Evaluation in Clinical Practice, vol. 15, no. 2, pp. 366-369, 2009.

[46] K. B. DeSalvo, N. Bloser, K. Reynolds, J. He, and P. Muntner, "Mortality prediction with a single general self-rated health question: a meta-analysis," Journal of General Internal Medicine, vol. 21, no. 3, pp. 267-275, 2006.

[47] M. Olfson, S. C. Marcus, M. Tedeschi, and G. J. Wan, "Continuity of antidepressant treatment for adults with depression in the United States," American Journal of Psychiatry, vol. 163, no. 1, pp. 101-108, 2006.

[48] S. H. Zuvekas and J. A. Fleishman, "Self-rated mental health and racial/ethnic disparities in mental health service use," Medical Care, vol. 46, no. 9, pp. 915-923, 2008.

[49] C. Cutrona and D. Russell, "The provisions of social relationships and adaptation to stress," in Advances in Personal Relationships, J. H. Jones and D. Perlman, Eds., vol. 1, pp. 3767, JAI Press, Greenwich, Conn, USA, 1987.

[50] Y. Gondo, N. Hirose, Y. Arai et al., "Functional status of centenarians in Tokyo, Japan: developing better phenotypes of exceptional longevity," Journals of Gerontology. Series A, vol. 61, no. 3, pp. 305-310, 2006.

[51] S. M. Samuelsson, B. Bauer Alfredson, B. Hagberg et al., "The Swedish Centenarian Study: a multidisciplinary study of five consecutive cohorts at the age of 100," International Journal of Aging and Human Development, vol. 45, no. 3, pp. 223-253, 1997.

[52] W. Herzog and A. Boomsma, "Small-sample robust estimators of noncentrality-based and incremental model fit," Structural Equation Modeling, vol. 16, no. 1, pp. 1-27, 2009.

[53] D. L. Jackson, "Revisiting sample size and number of parameter estimates: some support for the N:q hypothesis," Structural Equation Modeling, vol. 10, no. 1, pp. 128-141, 2003. 
[54] D. L. Jackson, "The effect of the number of observations per parameter in misspecified confirmatory factor analytic models," Structural Equation Modeling, vol. 14, no. 1, pp. 48 76, 2007.

[55] B. M. Byrne, Structural Equation Modeling with Amos: Basic Concepts, Applications, and Programming, Lawrence Erlbaum Associates, Mahwah, NJ, USA, 2001.

[56] R. B. Kline, Principles and Practice of Structural Equation Modeling, Guilford Press, New York, NY, USA, 2nd edition, 2005.

[57] L. K. Muthén and B. O. Muthén, Mplus User's Guide, Muthén and Muthén, Los Angeles, Calif, USA, 5th edition, 1998-2007.

[58] P. M. Bentler, "Comparative fit indexes in structural models," Psychological Bulletin, vol. 107, no. 2, pp. 238-246, 1990.

[59] M. W. Browne and R. Cudeck, "Single sample cross-validation indices for covariance structures," Multivariate Behavioral Research, vol. 24, pp. 445-455, 1989.

[60] L. T. Hu and P. M. Bentler, "Cutoff criteria for fit indexes in covariance structure analysis: conventional criteria versus new alternatives," Structural Equation Modeling, vol. 6, no. 1, pp. $1-55,1999$.

[61] R. C. MacCallum and J. T. Austin, "Applications of structural equation modeling in psychological research," Annual Review of Psychology, vol. 51, pp. 201-226, 2000.

[62] K. G. Jöreskog, "How large can a standardized coefficient be?" 1999, http://www.ssicentral.com/lisrel/techdocs/HowLargeCanaStandardizedCoefficientbe.pdf .

[63] K. Ell, "Social networks, social support, and health status: a review," The Social Service Review, vol. 58, no. 1, pp. 133-149, 1984.

[64] E. Rafaeli and M. E. J. Gleason, "Skilled support within intimate relationships," Journal of Family Theory \& Review, vol. 1, pp. 20-37, 2009.

[65] T. C. Antonucci, J. Akiyama, and J. E. Lansford, "Negative effects of close social relations," Family Relations, vol. 47, no. 4, pp. 379-384, 1998.

[66] T. E. Oxman, L. F. Berkman, S. Kasl, D. H. Freeman, and J. Barrett, "Social support and depressive symptoms in the elderly," American Journal of Epidemiology, vol. 135, no. 4, pp. 356-368, 1992.

[67] K. B. Wilson, "Historical evolution of assisted living in the United States, 1979 to the present," The Gerontologist, vol. 47 Spec No 3, pp. 8-22, 2007.

[68] T. E. Oxman, L. F. Berkman, S. Kasl, D. H. Freeman Jr., and J. Barrett, "Social support and depressive symptoms in the elderly," American Journal of Epidemiology, vol. 135, no. 4, pp. 356-368, 1992.

[69] B. Lakey and J. B. Drew, "A social-cognitive perspective on social support," in Sourcebook of Social Support and Personality, G. R. Pierce, B. Lakey, I. G. Sarason, and B. R. Sarason, Eds., pp. 107-140, Plenum Press, New York, NY, USA, 1997.

[70] E. S. Mankowski and R. S. Wyer, "Cognitive causes and consequences of perceived social support," in Sourcebook of Social Support and Personality, G. R. Pierce, B. Lakey, I. G. Sarason, and B. R. Sarason, Eds., pp. 141-165, Plenum Press, New York, NY, USA, 1997.

[71] A. Bandura, Social Foundations of Thought and Actions: A Social-Cognitive Theory, Prentice Hall, Englewood Cliffs, NJ, USA, 1986.

[72] S. Cobb, "Social support as a moderator of life stress," Psychosomatic Medicine, vol. 38, no. 5, pp. 300-314, 1976.
[73] S. Cobb, "Social support and health through the life course," in Aging from Birth to Death: Interdisciplinary Perspectives, M. W. Riledy, Ed., pp. 92-106, Westview Press, Boulder, Colo, USA, 1979.

[74] C. J. Holahan, R. H. Moos, and L. Bonin, "Social support, coping, and psychological adjustment: a resources model," in Sourcebook of Social Support and Personality, G. R. Pierce, B. Lakey, I. G. Sarason, and B. R. Sarason, Eds., pp. 169-186, Plenum Press, New York, NY, USA, 1997.

[75] L. W. Poon, G. M. Clayton, P. Martin et al., "The Georgia Centenarian Study," International Journal of Aging and Human Development, vol. 34, no. 1, pp. 1-17, 1992.

[76] K. Andersen-Ranberg, M. Schroll, and B. Jeune, "Healthy centenarians do not exist, but autonomous centenarians do: a population-based study of morbidity among danish centenarians," Journal of the American Geriatrics Society, vol. 49, no. 7, pp. 900-908, 2001.

[77] V. Gecas, "The social psychology of self-efficacy," Annual Review of Sociology, vol. 15, pp. 291-316, 1989.

[78] E. L. Mitty, "Assisted living: aging in place and palliative care," Geriatric Nursing, vol. 25, no. 3, pp. 149-163, 2004. 


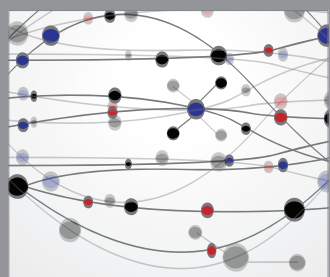

The Scientific World Journal
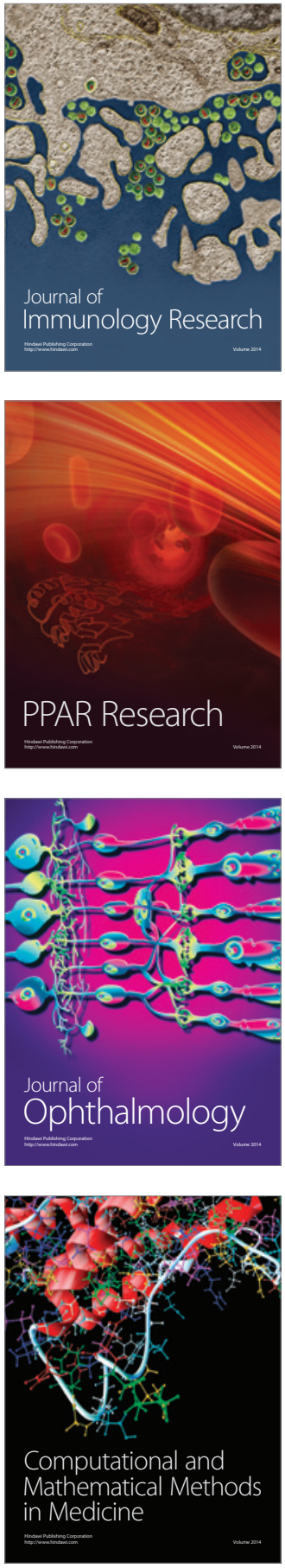

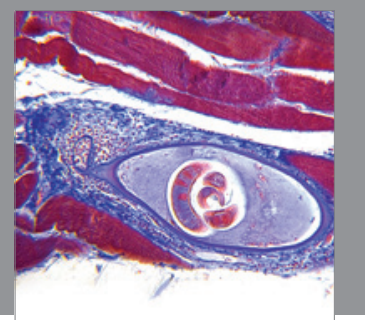

Gastroenterology

Research and Practice
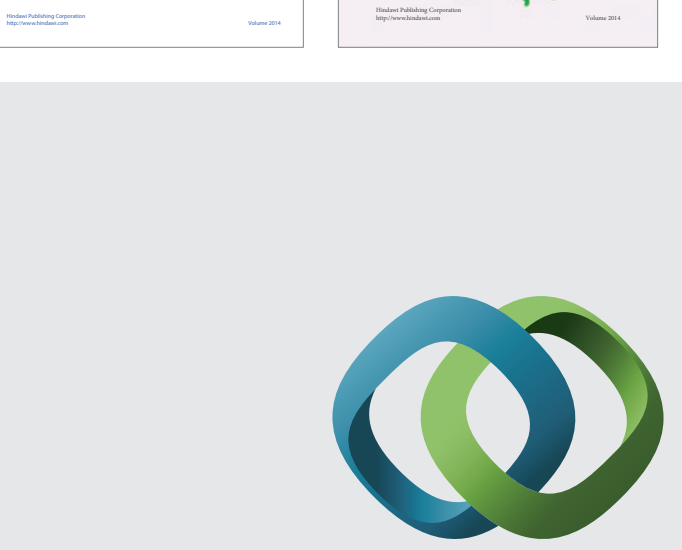

\section{Hindawi}

Submit your manuscripts at

http://www.hindawi.com
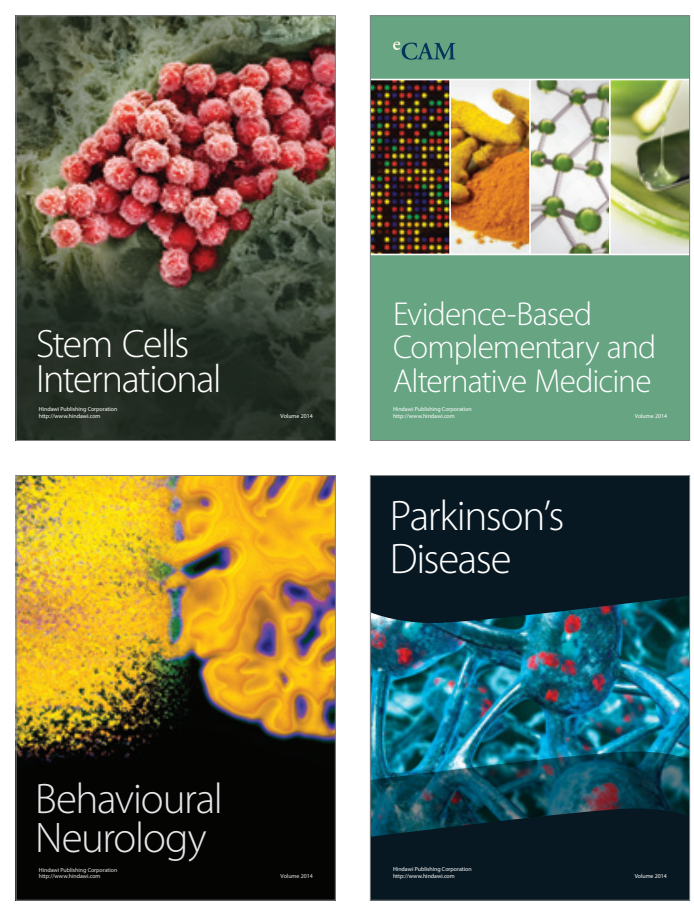

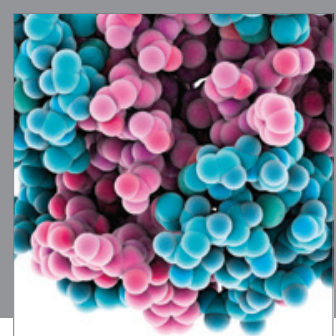

Journal of
Diabetes Research

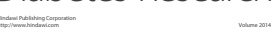

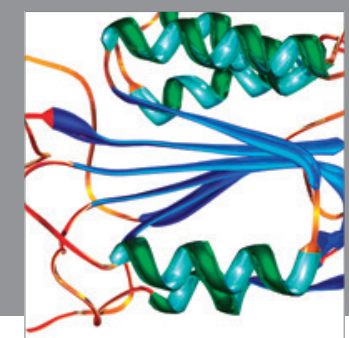

Disease Markers
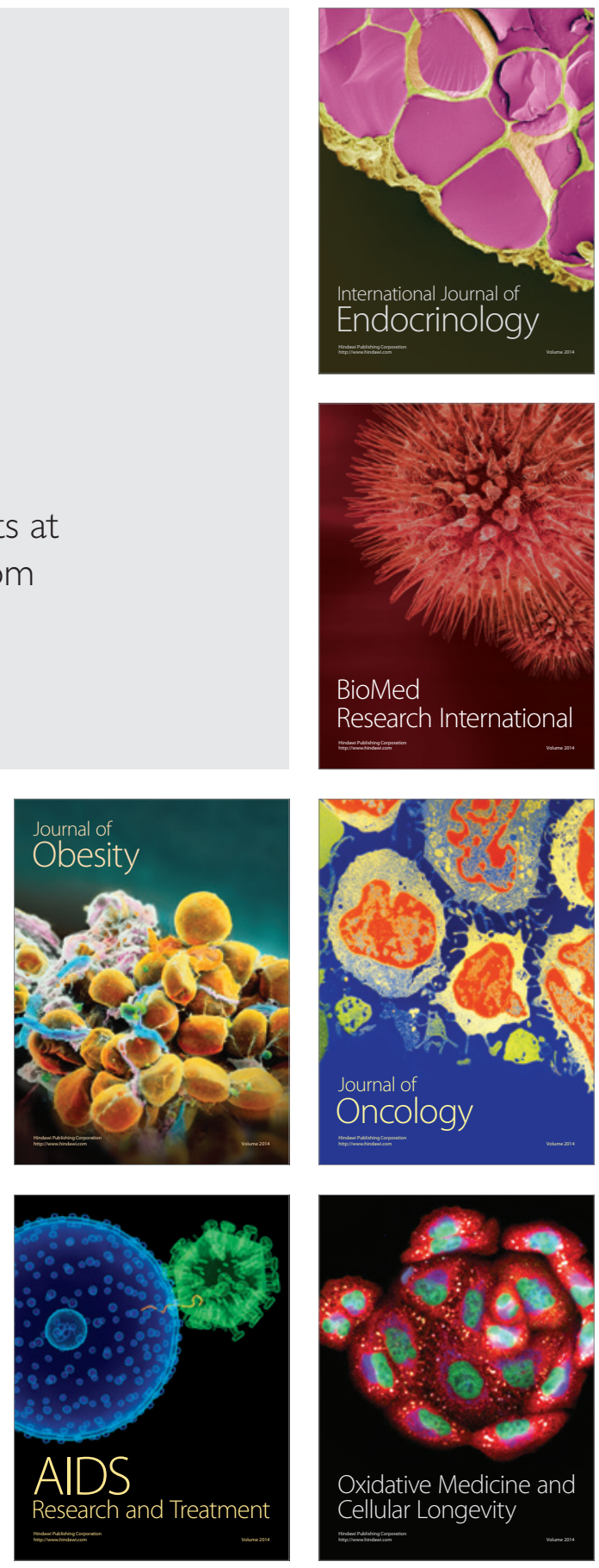